\title{
Mortality within hospital after resuscitation from ventricular fibrillation outside hospital
}

\author{
William Dickey, A A Jennifer Adgey
}

Regional Medical Cardiology Centre, Royal Victoria Hospital, Belfast W Dickey

A A J Adgey

Correspondence to Professor A A Jennifer Adgey, Regional Medical Cardiology Centre, Royal Victoria Hospital, Belfast BT12 6BA, Northern Ireland.

Accepted for publication 5 August 1991

\begin{abstract}
Objective-To determine factors related to mortality within hospital after successful resuscitation from ventricular fibrillation outside hospital by a mobile coronary care unit manned by a physician.
\end{abstract}

Design-Retrospective review of records of patients resuscitated and admitted to hospital between 1 January 1966 and 31 December 1987.

Setting-Mobile coronary care unit, coronary care unit, and cardiology department.

Patients-281 patients (227 male), aged 14-82 (mean 58) successfully resuscitated from ventricular fibrillation outside hospital of whom $182(65 \%)$ developed ventricular fibrillation before the arrival of the mobile coronary care unit. The aetiology of ventricular fibrillation was acute myocardial infarction in 194 patients $(69 \%)$, ischaemic heart disease without infarction in $71(25 \%)$, and other or unknown in $16(6 \%)$.

Main outcome measures-Death within hospital.

Results-There were 91 deaths in hospital $(32 \%)$. Factors on univariate analysis significantly associated with increased mortality were patient age $\geqslant 60$ years, previous myocardial infarction or cerebrovascular disease, prior digoxin or diuretic treatment, collapse without prior chest pain or with pain lasting 30 minutes or less, defibrillation delayed by $\geqslant 5$ min, $\geqslant$ four shocks required to correct ventricular fibrillation, left ventricular failure or pulmonary oedema and cardiogenic shock after successful defibrillation, and coma on admission to hospital. On multivariate analysis the most important factors (in rank order) were cardiogenic shock after defibrillation, coma on admission to hospital, age $\geqslant 60$ years and the requirement for four or more shocks to correct ventricular fibrillation.

Conclusions-The in-hospital mortality of patients resuscitated from ventricular fibrillation outside hospital was related to patient characteristics before the cardiac arrest and to the immediate haemodynamic and neurological status after correction of ventricular fibrillation as well as to factors at the resuscitation itself. The in-hospital mortality of this study compares favourably with the results obtained by units staffed by paramedical workers and emergency medical technicians, although 35\% (99/ 281) of the patients had ventricular fibrillation after the arrival of the mobile unit and defibrillation was thus rapid.

Since the feasibility of resuscitation from ventricular fibrillation outside hospital was first demonstrated in Belfast in $1966,{ }^{1}$ many mobile coronary care schemes have been established. In the United States there are now more than 300 prehospital coronary care programmes. ${ }^{2}$ Of the many published studies of outcome after prehospital cardiac arrest, most have concentrated on the relation between resuscitation-related factors (such as availability of bystander cardiopulmonary resuscitation and delay in defibrillation) and survival rather than patient characteristics before the arrest or haemodynamic status after correction of ventricular fibrillation. Furthermore, few studies have considered factors specifically related to death within hospital for patients who survive to be admitted. We describe 281 patients resuscitated from ventricular fibrillation outside hospital by the Royal Victoria Hospital's mobile coronary care unit and we assess factors related to inhospital mortality.

\section{Patients and methods \\ PATIENTS}

We studied patients who were resuscitated outside hospital after ventricular fibrillation developed and who were admitted to hospital by the Royal Victoria Hospital mobile coronary care unit between 1 January 1966 and 31 December 1987. Patients developed ventricular fibrillation before or after the arrival of the mobile unit. When ventricular fibrillation developed after the mobile unit's arrival, patients received immediate defibrillation. Patients were not included in the study if ventricular fibrillation was iatrogenic - that is, if it occurred during treatment of ventricular tachycardia or asystole.

\section{COLLECTION OF DATA}

Since the mobile unit started operation, patient characteristics, circumstances of arrest, resus- 
citation details, and condition after successful resuscitation have been recorded on standardised forms. The following factors were studied to determine their relevance to outcome:

Patient characteristics-sex, age, previous history of myocardial infarction, previous stable angina or chronic cardiac dyspnoea (New York Heart Association grade II or greater), previous hypertension, diabetes mellitus or cerebrovascular event (stroke or transient ischaemic attack), previous drug treatment (digoxin, diuretics, $\beta$ blocking and antiarrhythmic agents), smoking history.

Aetiology and circumstances of arrestaetiology, site of infarction if present, year, time, place, ventricular fibrillation before or after the arrival of the mobile unit, presence or absence of chest pain and its duration before ventricular fibrillation.

Resuscitation details-presence or absence of cardiopulmonary resuscitation before defibrillation, cardiopulmonary resuscitation operator, delay in starting cardiopulmonary resuscitation after collapse where given, delay in defibrillation, number of shocks required to correct ventricular fibrillation (defined as the total number of shocks administered at the time of the initial arrest outside hospital before a stable rhythm was achieved and maintained even if ventricular fibrillation recurred after the initial resuscitation at the time of the initial arrest).

Condition after successful defibrillation-left ventricular failure or pulmonary oedema, cardiogenic shock (systolic blood pressure $<80 \mathrm{~mm} \mathrm{Hg}$ with peripheral circulatory shutdown), coma on admission to hospital.

Statistical analysis was performed with the Statistical Package for the Social Sciences-II program on a Digital Professional 350 microcomputer. To test single factors for significance in influencing in-hospital mortality we used a $\chi^{2}$ test with Yates's correction on $2 \times 2$ contingency tables. We used the multiple regression program of Statistical Package for the Social Sciences-II for multivariate analysis in order to determine the most significant factors and rank them in order.

\section{Results}

PATIENTS

Between 1 January 1966 and 31 December 1987, 281 patients (227 male; age range 14-82; mean (1 SD) 58 (12) years) in whom ventricular fibrillation developed outside hospital were successfully resuscitated by the Royal Victoria Hospital mobile coronary care unit and were admitted to hospital. The cardiac arrest was witnessed in all except one patient. One hundred and eighty two $(65 \%)$ patients developed ventricular fibrillation before the arrival of the mobile unit.

\section{AETIOLOGY}

The aetiology of ventricular fibrillation was identified as acute myocardial infarction on the basis of electrocardiograph and/or serial cardiac enzyme changes in $194(69 \%)$ patients. The site of infarction was inferior or posterior in 66 patients $(34 \%)$, anterior in $121(62 \%)$, and was unknown in seven $(4 \%)$. Seventy one $(25 \%)$ of the 281 patients had ischaemic heart disease but no evidence of acute myocardial infarction at the time of ventricular fibrillation. Thus coronary artery disease, with or without acute myocardial infarction, caused ventricular fibrillation in $265(94 \%)$ of the patients seen. The aetiology was not related to coronary artery disease in 13 patients and was unknown in three.

\section{IN-HOSPITAL MORTALITY}

Of the 281 patients, 91 (32\%) died in hospital; thus 190 patients $(68 \%)$ survived to be discharged. Of the 91 in-hospital deaths, 41 (45\%) occurred within 48 hours of the initial arrest and $50(55 \%)$ occurred $\geqslant 48$ hours later. Death was due to intractable ventricular fibrillation (23 patients), cerebral anoxia (24), cardiogenic shock (nine), respiratory failure (13), cardiac failure (17), and bradyasystole (five).

FACTORS RELATED TO IN-HOSPITAL MORTALITY AND SURVIVAL TO DISCHARGE

Patient characteristics

Patients who survived to leave hospital were significantly younger $(56 \cdot 0(12))$ than those who died before discharge $(60.8(11))(p<0.01)$.

Table 1 Patient characteristics significantly associated with in-hospital mortality (univariate analysis) (\%)

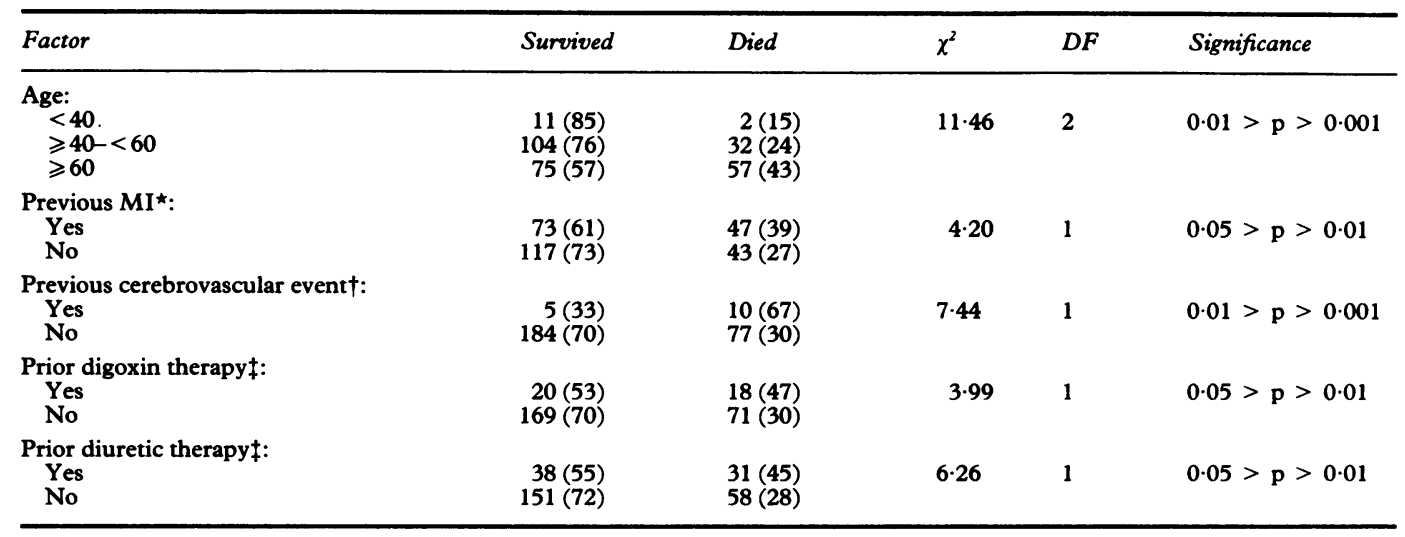

DF, degrees of freedom, MI, myocardial infarction.

^One missing observation, + five missing observations, $\ddagger$ three missing observations. 
Table 2 Factors related to the cardiac arrest that were significantly associated with in-hospital mortality (univariate analysis) (\%)

\begin{tabular}{|c|c|c|c|c|c|}
\hline Factor & Survived & Died & $\chi^{2}$ & $D F$ & Significance \\
\hline $\begin{array}{l}\text { VF before arrival of mobile unit: } \\
\text { Yes } \\
\text { No }\end{array}$ & $\begin{array}{r}112(62) \\
78(79)\end{array}$ & $\begin{array}{l}70(38) \\
21(21)\end{array}$ & 7.94 & 1 & $0.01>p>0.001$ \\
\hline $\begin{array}{l}\text { Chest pain before VF: } \\
\text { Yes } \\
\text { No }\end{array}$ & $\begin{array}{r}136(72) \\
54(59)\end{array}$ & $\begin{array}{l}53(28) \\
38(41)\end{array}$ & $4 \cdot 38$ & 1 & $0.05>p>0.01$ \\
\hline $\begin{array}{l}\text { Duration of chest pain before VF: } \\
\quad \leqslant 30 \mathrm{~min} \\
>30 \mathrm{~min}<4 \mathrm{~h} \\
\geqslant 4 \mathrm{~h}\end{array}$ & $\begin{array}{l}16(53) \\
106(76) \\
14(70)\end{array}$ & $\begin{array}{r}14(47) \\
33(24) \\
6(30)\end{array}$ & $6 \cdot 47$ & 2 & $0.05>p>0.01$ \\
\hline $\begin{array}{l}\text { Delay in defibrillation }{ }^{\star} \\
<5 \mathrm{~min} \\
5-9 \mathrm{~min} \\
\geqslant 10 \mathrm{~min}\end{array}$ & $\begin{array}{r}106(75) \\
38(62) \\
45(60)\end{array}$ & $\begin{array}{l}36(25) \\
23(38) \\
30(40)\end{array}$ & 6.00 & 2 & $0.05>p>0.01$ \\
\hline $\begin{array}{l}\text { Shocks to correct } \operatorname{VF}(n)^{\star}: \\
\quad<4 \\
\geqslant 4\end{array}$ & $\begin{array}{r}138(72) \\
50(57)\end{array}$ & $\begin{array}{l}53(28) \\
37(43)\end{array}$ & $5 \cdot 31$ & 1 & $0.05>p>0.01$ \\
\hline
\end{tabular}

DF, degrees of freedom; VF, ventricular fibrillation.

ॠThree missing observations.

The influence of patient age on survival to leave hospital was confirmed by $\chi^{2}$ testing (table 1 ). Single-factor analysis showed that the following patient characteristics were also significantly $(p<0.05)$ associated with in-hospital mortality: previous myocardial infarction, previous cerebrovascular event, prior digoxin therapy, and prior diuretic therapy.

\section{Aetiology and circumstances of arrest}

Single factor analysis showed that the following circumstances of the cardiac arrest were significantly associated with death in hospital (table 2): ventricular fibrillation developing before the arrival of the mobile unit, collapse without preceding chest pain, pain lasting $\leqslant 30$ minutes before collapse for patients who had chest pain, delay in defibrillation $\geqslant 5$ minutes after collapse, and the requirement for four or more shocks to correct ventricular fibrillation at the initial arrest and to allow a stable rhythm to be maintained.

\section{Condition after successful defibrillation}

The presence of the following features after successfuldefibrillation was significantly related to in-hospital mortality on single factor analysis (table 3): left ventricular failure or pulmonary oedema, cardiogenic shock, and failure to recover consciousness by the time of admission to hospital.
Factors not related to outcome

These were sex, previous stable angina, previous chronic cardiac dyspnoea, history of hypertension, diabetes mellitus, prior treatment with $\beta$ blockers or antiarrhythmic agents, a history of smoking, aetiology of ventricular fibrillation, site of infarct if ventricular fibrillation was caused by acute myocardial infarction, year, time and place of ventricular fibrillation, presence or absence of cardiopulmonary resuscitation before defibrillation if patients had ventricular fibrillation before the arrival of the mobile unit, and for patients who received cardiopulmonary resuscitation, the delay to resuscitation and type of operator.

\section{Multivariate analysis}

Factors shown to be significantly related to inhospital mortality on univariate analysis were also analysed by a stepwise forward algorithm with factors entered as binary variables.

Factors of greatest significance in predicting in-hospital mortality were cardiogenic shock after successful defibrillation, coma on admission to hospital, age $\geqslant 60$ years, and the need for four or more shocks to correct ventricular fibrillation (table 4).

\section{Discussion}

The initial experience with the Royal Victoria

Table 3 Factors after successful defibrillation significantly associated with in-hospital mortality (univariate analysis) $(\%)$

\begin{tabular}{|c|c|c|c|c|c|}
\hline Factor & Survived & Died & $\chi^{2}$ & $D F$ & Significance \\
\hline $\begin{array}{l}\text { Cardiac failure }{ }^{\star}: \\
\text { No } \\
\text { Mild/moderate } \\
\text { Pulmonary oedema }\end{array}$ & $\begin{array}{r}127(73) \\
52(65) \\
10(40)\end{array}$ & $\begin{array}{l}48(27) \\
28(35) \\
15(60)\end{array}$ & $11 \cdot 33$ & 2 & $0.01>p>0.001$ \\
\hline $\begin{array}{l}\text { Cardiogenic shock: } \\
\text { Yes } \\
\text { No }\end{array}$ & $\begin{array}{c}1(4) \\
189(74)\end{array}$ & $\begin{array}{l}24(96) \\
67(26)\end{array}$ & $47 \cdot 58$ & 1 & $p<0.001$ \\
\hline $\begin{array}{l}\text { Coma on hospital adm } \\
\text { Yes } \\
\text { No }\end{array}$ & $\begin{array}{r}65(56) \\
125(76)\end{array}$ & $\begin{array}{l}51(44) \\
40(24)\end{array}$ & $11 \cdot 22$ & 1 & $\mathrm{p}<0.001$ \\
\hline
\end{tabular}

*One missing observation. DF, degrees of freedom. 
Table 4 Factors significantly $(p<0.05)$ related to in-hospital mortality on stepwise multiple regression analysis

\begin{tabular}{llll}
\hline Step & Factor & $\begin{array}{l}\text { Standardised } \\
\text { Coefficient }\end{array}$ & F value \\
\hline 1 & Cardiogenic shock after defibrillation & 0.443 & $70 \cdot 62$ \\
2 & Coma on hospital admission & $0 \cdot 181$ & $10 \cdot 73$ \\
3 & Age $\geqslant 60$ & $0 \cdot 138$ & $6 \cdot 88$ \\
4 & $\geqslant 4$ shocks to correct VF & $0 \cdot 112$ & $4 \cdot 16$ \\
\hline
\end{tabular}

VF, ventricular fibrillation. within hospital was confirmed both on univariate and on multivariate analysis, where on stepwise analysis it appeared after cardiogenic shock and coma following defibrillation. Other studies have confirmed the association of patient age and outcome within hospital after resuscitation from out-of-hospital ventricular fibrillation and other cardiac arrest rhythms. ${ }^{15-17}$

Of other patient characteristics, previous history of myocardial infarction, cerebrovascular event, and prior digoxin or diuretic therapy were associated with increased in-hospital mortality. Few studies have assessed any of these factors. Weaver et al did not find prior digoxin or diuretic therapy to be significantly related to in-hospital mortality after resuscitation from ventricular fibrillation out of hospital. ${ }^{18}$ The increased in-hospital mortality associated with digoxin and diuretic therapy in the present study may reflect an increased likelihood of collapse without warning chest pain and hence delayed defibrillation. Alternatively, these drugs may be indicators of poor cardiac function. An increased in-hospital mortality for patients resuscitated from out of hospital ventricular fibrillation with a previous history of cardiac failure has been reported. ${ }^{16}$

\section{Circumstances of cardiac arrest}

Ventricular fibrillation occurring before the arrival of the mobile unit and defibrillation delayed by $\geqslant 5$ minutes were significantly associated with increased in-hospital mortality and confirm the importance of early defibrillation. ${ }^{19}$ Further support is provided by the increased mortality in patients who collapsed without warning chest pain (and in whom, therefore, defibrillation must have been delayed) and in patients who had pain lasting $\leqslant 30$ minutes who because of delays in summoning help were more likely to have collapsed before the arrival of the mobile unit. The association between the number of shocks required to correct ventricular fibrillation and outcome was confirmed both on univariate and multivariate analysis. Dunn et al confirmed an increased in-hospital mortality for patients who require $\geqslant 4$ shocks to terminate in-hospital or out-of-hospital ventricular fibrillation, ${ }^{20}$ and Hargarten et al showed a linear decrease in survival with each shock delivered (up to five) for patients receiving treatment for ventricular fibrillation outside hospital. ${ }^{7}$

\section{Condition after successful defibrillation}

Univariate analysis showed that left ventricular failure and cardiogenic shock after successful defibrillation were significant predictors of inhospital mortality; and multivariate analysis showed cardiogenic shock to be the most important predictor of death in hospital. Few studies of patients resuscitated from ventricular fibrillation out of hospital have considered the influence of haemodynamic status after resuscitation on survival. Liberthson et al reported an in-hospital mortality of $92 \%$ for patients who had cardiogenic shock after resuscitation from ventricular fibrillation out of hospital and of $64 \%$ for patients with conges-
FACTORS RELATED TO IN-HOSPITAL MORTALITY Patient characteristics

The importance of age in relation to death 
tive heart failure compared with $58 \%$ for all patients. ${ }^{5}$ Studies of ventricular fibrillation in hospital confirm the adverse influence of cardiac failure and cardiogenic shock at the time of ventricular fibrillation on in-hospital mortality. ${ }^{2122}$

Unconsciousness on admission to hospital was a significant predictor of in-hospital mortality both on univariate and multivariate analysis. Again, the importance of early defibrillation in speeding neurological recovery and hence survival has been confirmed elsewhere. ${ }^{2324}$

In conclusion, our results show that a favourable outcome for discharge from hospital after resuscitation from ventricular fibrillation out of hospital is more likely in young patients with no prior cardiac history who have immediate or early defibrillation, no haemodynamic abnormality, and who recover consciousness rapidly after correction of ventricular fibrillation. Wider availability of early defibrillation outside hospital particularly in the home, at work, and in public places by automatic, semi-automatic, and trans-telephonic defibrillators will increase the likelihood of survival after the onset of ventricular fibrillation outside hospital.

1 Pantridge JF, Geddes JS. A mobile intensive-care unit in the management of myocardial infarction. Lancet 1967; managem

2 Eisenberg MS, Bergner L, Hearne T. Out-of-hospital cardiac arrest: a review of major studies and a proposed uniform reporting system. Am $J$ Public Health 1980;70:236-40.

3 Adgey AAJ, Nelson PG, Scott ME, Geddes JS, Allen JD, Zaidi SA, et al. Management of ventricular fibrillation outside hospital. Lancet 1969;1:1169-71.

4 Baum RS, Alvarez H, Cobb LA. Survival after resuscitation from out-of-hospital ventricular fibrillation. Circulation 1974;50:1231-5.

5 Liberthson RR, Nagel EL, Hirschmann JC, Nussenfeld SR. Prehospital ventricular defibrillation: prognosis and follow-up course. N Engl J Med 1974;291:317-21.

6 Goldstein S, Landis JR, Leighton R, Ritter G, Vasu CM, Wolfe RA, et al. Predictive survival models for resus- citated victims of out-of-hospital cardiac arrest with coronary heart disease. Circulation 1985;71:873-80.

7 Hargarten KM, Stueven HA, Waite EM, Olson DW, Mateer JR, Aufderheide TP, et al. Prehospital experience with defibrillation of coarse ventricular fibrillation: a tenyear review. Ann Emerg Med 1990;19:157-62.

8 Webb SW, Adgey AAJ, Pantridge JF. Autonomic disturbance at onset of acute myocardial infarction. BMJ bance at onset
1972;iii:89-92.

9 Einarsson O, Jakobsson F, Sigurdsson G. Advanced cardiac life support in the pre-hospital setting: the Reykjavik experience. J Intern Med 1989;225:129-35.

10 Myerburg RJ, Conde CA, Sung RJ, Mayorga-Cortes A Mallon SM, Sheps DS, et al. Clinical electrophysiologic and hemodynamic profile of patients resuscitated from prehospital cardiac arrest. Am J Med 1980;68:568-76.

11 Aprahamian C, Thompson BM, Gruchow HW, Mateer JR, Tucker JF, Stueven HA, et al. Decision making in prehospital sudden cardiac arrest. Ann Emerg Med 1986;15:445-9.

12 Stults KR, Brown DD, Kerber RE. Efficacy of an automated external defibrillator in the management of out-of-hospital cardiac arrest: validation of the diagnostic algorithm and
initial clinical experience in a rural environment. Circulainitial clinical exper $1986 ; 73: 701-9$.

13 Cummins RO, Eisenberg MS, Litwin PE, Graves JR, Hearne TR, Hallstrom AP. Automatic external defibrillators used by emergency medical technicians: a controlled clinical trial. JAMA 1987;257:1605-10.

14 Weaver WD, Hill D, Fahrenbruch CE, Copass MK, Martin JS, Cobb LA, et al. Use of the automatic external defibrillator in the management of out-of-hospital cardiac arrest. $N$ Engl J Med 1988;319:661-6.

15 Ritter G, Wolfe RA, Goldstein S, Landis JR, Vasu CM Acheson A, et al. The effect of bystander CPR on survival of out-of-hospital cardiac arrest victims. Am Heart 1985;110:932-7.

16 Hallstrom AP, Cobb LA, Swain M, Mensinger K. Predictors of hospital mortality after out-of-hospital cardiopulmonary resuscitation. Crit Care Med 1985;13:927-9.

17 Tresch DD, Thakur RK, Hoffmann RG, Olson D, Brooks HL. Should the elderly be resuscitated following out-ofhospital cardiac arrest? $A m J$ Med 1989;86:145-50.

18 Weaver WD, Cobb LA, Hallstrom AP, Fahrenbruch C Copass MK, Ray R. Factors influencing survival after outof-hospital cardiac arrest. J Am Coll Cardiol 1986;7 $752-7$.

19 Eisenberg MS, Hallstrom AP, Copass MK, Bergner L, Short F, Pierce J. Treatment of ventricular fibrillation: emergency medical technician defibrillation and paramedic services. JAMA 1984;251:1723-6.

20 Dunn HM, McComb JM, MacKenzie G, Adgey AAJ. Survival to leave hospital from ventricular fibrillation. $A m$ Heart $J$ 1986;112:745-51.

21 Lawrie DM, Higgins MR, Godman MJ, Oliver MF, Julian DG, Donald $\mathrm{KW}$. Ventricular fibrillation complicating acute myocardial infarction. Lancet 1968;ii:523-8.

22 Dubois Ch, Smeets JP, Demoulin JCl, Piérard L, Foidart G Henrard $L$, et al. Incidence, clinical significance and prognosis of ventricular fibrillation in the early phase of myocardial infarction. Eur Heart $J$ 1986;7:945-51.

23 Weaver WD, Copass MK, Bufi D, Ray R, Hallstrom AP, Cobb LA. Improved neurologic recovery and survival after early defibrillation. Circulation 1984;69:943-8.

24 Longstreth WT, Inui TS, Cobb LA, Copass MK Neurologic recovery after out-of-hospital cardiac arrest. Ann Intern Med 1983;98:588-92. 